\title{
Load flexibility potential for the residential, commercial and industrial sectors in Brazil
}

\author{
Géremi Gilson Dranka ${ }^{\mathrm{a}, \mathrm{b}}$, Paula Ferreira ${ }^{\mathrm{c}}$
}

\author{
${ }^{a}$ ALGORITMI Research Center, University of Minho, Guimarães, Portugal, geremidranka@ gmail.com
}

${ }^{b}$ Department of Electrical Engineering, Federal University of Technology, Paraná, Pato Branco, Brazil

cALGORITMI Research Center, University of Minho, Guimarães, Portugal, paulaf@dps.uminho.pt

\begin{abstract}
The flexibility in grid operations has become a valuable solution to address the several problems brought about the growth of intermittent renewable generation and the use of Demand Response (DR) measures has emerged as a potential contributor to address this challenge. To the best of authors knowledge, the assessment of the theoretical DR potential for the Brazilian power sector has not yet fully addressed in the available literature. This paper is a first attempt to establish the theoretical load flexibility potential for the Brazilian power sector across the residential, commercial and industrial sectors. We provide the assessment of the future DR potential (up to 2050) based on a set of technical assumptions. The strengths of this study include two central issues addressed: (1) a sectoral analysis and (2) a regional analysis by broadly splitting up the Brazilian power system into four main subsystems. Our findings reveal that the overall maximum hourly theoretical DR potential in Brazil is expected to double, increasing from $12.8 \mathrm{GW}$ in 2017 to almost $25.6 \mathrm{GW}$ by 2050 . Findings of this study point out that the majority of the demand-side response potential may lie in the industrial sector. Lower but a still substantial potential for the residential and commercial sectors were also identified. The high expected increase in the overall electricity DR potential for the residential sector is driven mainly by the increase in both the number of households and the number of appliances per house.
\end{abstract}

Keywords: Demand Response (DR); Demand-side Management (DSM); Load Flexibility; Regional Analysis; Brazilian Power Sector.

\begin{tabular}{|llll|}
\hline Nomenclature & & \\
$E_{\text {year_com }}^{k}$ & Annual Electricity Consumption (commercial) & $P_{\text {max_ind }}^{k}$ & Maximum Installed Capacity (industrial) \\
$E_{\text {year_ind }}^{k}$ & Annual Electricity Consumption (industrial) & $P_{\text {max_res }}^{k}$ & Maximum Installed Capacity (residential) \\
$E_{\text {year_res }}^{k}$ & Annual Electricity Consumption (residential) & $n_{F L H}^{k}$ & Number of Full Load Hours \\
$E_{\text {year_self_ind }}^{k}$ & Annual Industrial Self-Electricity Production & $N_{h_{-} \text {year }}$ & Number of Hours in a Year \\
$E_{\text {total_year_ind }}^{k}$ & Total Annual Electricity Demand (industrial) & $n_{\text {house }}$ & Number of Households \\
$s_{\text {com }}^{k}$ & Average Demand Share (commercial) & $F D^{k}$ & Percentage of Flexible Demand \\
$s_{\text {util }}^{k}$ & Capacity Utilization Level & $A_{\text {year }}^{k}$ & Production Capacity \\
$E_{\text {com }}^{k}$ & Commercial Sector Demand & $f_{\text {rev }}^{k}$ & Revision Outages \\
$E_{\text {hourly }}^{k}$ & Hour Electricity Demand & $P_{\text {unit }}^{k}$ & Specific Capacity of Each Appliance \\
$E_{\text {hourly }(i)}^{k}$ & Hourly Theoretical DR Potential & $E_{\text {spec }}^{k}$ & Specific Electricity Consumption \\
$f_{\text {eq }}^{k}$ & Market Penetration Rate of Each Appliance & $E_{\text {unit }}^{k}$ & Specific Electricity Consumption of Each \\
$P_{\text {max_com }}^{k}$ & Maximum Installed Capacity (commercial) & $D_{p r o f i l e}^{k}$ & Appliance \\
& & & Typical Load Profile \\
\hline
\end{tabular}




\section{Introduction}

Driven by the economic growth and changes in attitudinal and consumer behavior, the energy demand rose globally by nearly $2 \%$ in 2017 which represented the fastest growth in the decade since 2010. Improvements due to Energy Efficiency Measures (EEMs) prevented $12 \%$ more Green-house Gas (GHG) emissions in 2017 since 2010 [1]. Ref. [2] highlight the potential of both Renewable Energy Sources (RES) and EMMs to support the energy transition in the global effort to mitigate climate change and contribute to sustainable development goals. However, many potential challenges (e.g. technical, economic and regulatory) brought about by the high growth of Variable Renewable Energy (VRE) have been pointed out in the literature particularly in the last couple of years. To give a well-known example for the sake of clarity, the flexibility in grid operations has become a valuable solution to address the several problems brought about the growth of VRE - especially from wind and solar power systems - and the use of Demand-side Management (DSM) strategies (particularly from Demand Response (DR) resources) has emerged as a potential contributor to address this challenge.

The transition towards a smart grid power system for the specific case of Brazil was recently addressed in Ref. [3]. A systematic literature review regarding the concept of smart energy systems is undertaken by Ref. [4]. Ref. [5] addressed specifically the role of smart energy systems and the 4th district heating generation. The concept of DSM in district heating systems has been taken into account recently by Ref. [6]. Based on a statistical approach and considering an urban district level, the waste heating potential for sewage systems is assessed by Ref. [7]. The coupling between district heating and electrical distribution grids is assessed by Ref. [8] in which the authors highlight the potential of the proposed methodology to technically address the coupling between heat and power networks.

The consumers will also play a key role in the electricity market in the future [9] and the growing market share of smart appliances brought about the evolution of smart grids may strongly facilitate the insertion of demand-side resources such as air conditioning, washing machines, and refrigerators without compromising user comfort. Although there are currently only a few of DR programs in 
Brazil, it is projected a considerable growth along with the years to come across all sectors, particularly for the residential one. Brazil's population has reached the level of 208.4 million in 2018 according to the Brazilian Economic \& Geographical Institute (in Portuguese, IBGE). The number of households in Brazil is expected to increase about 40 million in 2050 comparatively to 2012 [9] and the average per capita income is expected to be slightly lower than US\$36 thousands/person (2050) which currently can be compared to the average level of Germany and France, for example. Köppen's climate classification map for Brazil (illustrated in Fig. 1Fig. 1) shows the different current climate conditions which strongly varies from North to South regions ([41][42]). Therefore, the growth of population coupled with the future climate change challenges will require a set of integrated approaches for the energy sector which may couple the integrated benefits of DSM strategies, for example.

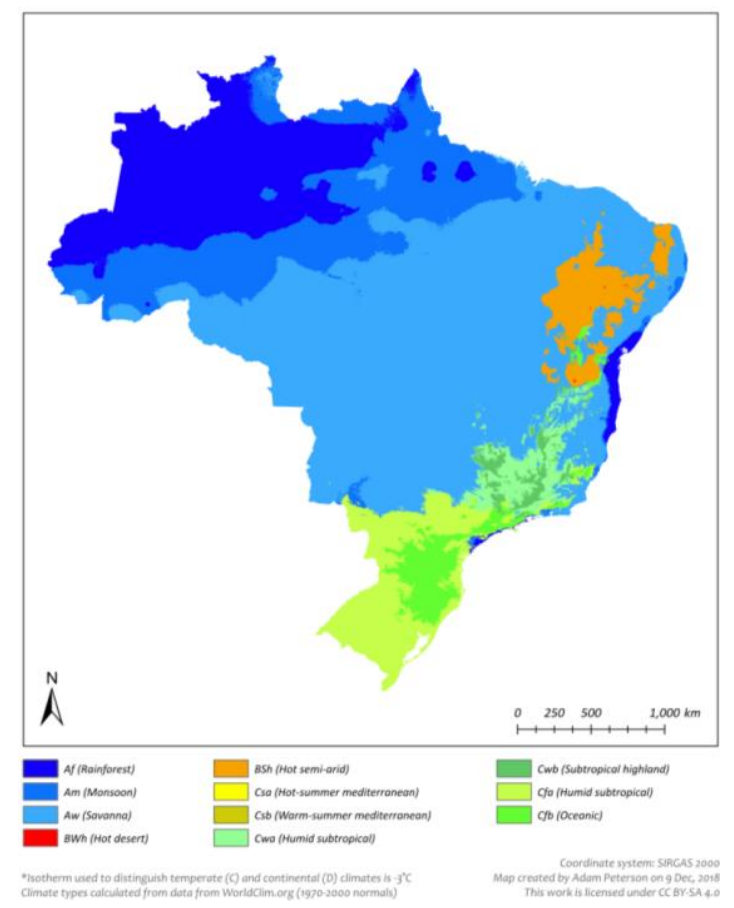

Fig. 1. Köppen's climate classification map for Brazil (Ref. [41]).

A well-known example for the recent developments of DR strategies in Brazil, specifically focusing on the residential sector, comprises the implementation of the Tariff Flag System (2013) [10], the

Commented [GD1]: - It would be useful to present some relevant information about the four regions (climate, industry, population, etc.), and their position on the map.

Commented [GD2R1]: Tentei colocar essa figura pra mostrar um pouco do "climate" no país. Lá embaixo inclui uma figura que mostra as regiões do país. Veja se a prof. Paula concorda... 
White Hourly Tariff (2016) [11] and the possibility of the electricity prepayment [12]. The White Hourly Tariff, for example, is considered a type of Time of Use (TOU) rate, in which the price of electricity is split up into off-peak, mid-peak and on-peak periods [13]. These recent new policies and regulations also expect to motivate price-based DR programs in the country. For the industrial sector, a pilot DR program [14] (focused particularly on large industrial consumers of North and Northwest regions) was implemented by the Brazilian Electricity Regulatory Agency (in Portuguese, ANEEL) in 2017. This DR program is based on previous information given by the consumers regarding their willingness to accept a given level of load reductions bids and load recovery [15]. The low DR contribution in the country intensified the electricity supply problems brought about by severe droughts occurred in the country in 2014. This also led to a considerable increase in electricity generation from thermal power sources [16]. The current status of DR in Brazil is therefore very restricted, with only a few DR programs effectively implemented, although the authorities of the sector agree with the increasing importance of DR strategies to delineate the medium and long-term strategic energy plan of the country [17].

Most of the previous studies (e.g. [18-22]) that investigate DR issues (across different countries) are largely based upon qualitative approach analysis [23]. In recent years, however, there has been a growing number of publications focusing on the assessment of the different categories of DR potentials, but these analyses are particularly limited to European countries (see for example [2428]). A systematic review of the different categories of DR potentials (i.e. theoretical, technical, economic, and achievable ${ }^{1}$ ) was recently addressed by the authors of Ref. [29] which also pointed out a lack of understanding in the available literature regarding the different categories of DR potentials. The theoretical DR potential can be defined as the overall consumers' potential suitable for $\mathrm{DR}^{2}$. Therefore, the theoretical DR potential does not take into account technical (e.g. the shifting time),

\footnotetext{
${ }^{1}$ This last concept (i.e. achievable) can be divided into the Maximum Achievable Potential (MAP) and the Realistic Achievable Potential (RAP). The achievable DR potential has also been interchangeably referred by the available literature as social, practical, market, realizable, feasible or even acceptable DR potential.

${ }^{2}$ This definition is used along with this paper to refer to the theoretical DR potential.
} 
economic (e.g. investment and operational costs of DR implementation) or practical (e.g. the level of consumers' acceptance) restrictions [23,26,30].

A search of the literature revealed few studies which addressed the contribution of DR in the longterm for the case of the Brazilian power system. A detailed examination of the literature also revealed little research (e.g. [31]) which have attempted to quantitatively assess the potential of DR for the specific case of Brazil. The authors of Ref. [31], for example, addressed the specific role of sector coupling using a long-term energy model and considered a simplified approach for estimating the DR potential in the country. In order to account for the load flexibility potential, Ref. [31] considered (partly) the DR potential of both the commercial and industrial sectors. The authors concluded that because of the high renewable potential in the country (mostly from hydropower resources [32]) the contribution of DR strategies is limited to load balancing, but great potential for peak load reductions (estimated to be about $3.3 \mathrm{GW}$ ) could be projected for the future.

Therefore, the vast majority of researchers have not considered a holistic assessment of the load flexibility potential, particularly for developing countries, such as the case of Brazil. This may be understood by a set of factors. Firstly, this is considered a complex task and rely mostly on extensive data collection and analysis. The data scarcity (e.g. the load profile for each sector) figures out as another potential problem and studies need to rely on a set of assumptions based on estimated data. In this context, few research papers have been able to draw on any structured research into the current and future DR potentials for the case of the Brazilian power sector. The results are somewhat limited to oversimplified analyses, considering for instance, only partly the DR potential and usually focusing on particular sectors. The existing assessments therefore may not be representative in terms of the full DR potential available across the main sectors in the country.

Therefore, thus far, there are few works addressing (1) the assessment of the theoretical DR potential for the Brazilian power sector and (2) the existing analysis focuses on specific sectors and/or regions within the country. To the best of authors knowledge, a comprehensive assessment of DR potential for the Brazilian power sector is lacking so far. We highlight the need to address the load 
flexibility potential in the country based upon a holistic assessment. This paper thus aims to be twofold. Firstly, it attempts to systematically assess the theoretical DR potential of selected applications across different sectors (i.e. residential, commercial and industrial) and regions (i.e. Northwest (NE), North (NO), Southwest (SE) and South (SO)) for the reference year (2017). Then, the theoretical DR potential for future years (until 2050) will be estimated based on the data extrapolation and considering a set of technical assumptions. The innovative aspects and the strengths of this paper relies on the fact that according to the best of authors' knowledge this is the first attempt to quantitatively evaluate the potential of load flexibility in the country across regions and sectors. The replication of the methodology approach would be also beneficial to estimate the load flexibility potential for other countries.

This paper contextualizes the topic under study by giving a brief overview of the recent developments in the area in this first section. The remaining part of the paper proceeds as follows. Section 2 is concerned with the methodology employed in this study, including the data collection techniques and the approach used to estimate the theoretical DR potential for each sector. The third section presents the findings of the research, focusing on the different levels for the theoretical DR potential across the residential, industrial and commercial sectors. The final section summarizes the main findings of this research and also provide possible future pathways by including a lively discussion of the implication of the results. .

\section{Methodology}

A comprehensive literature review was firstly undertaken in order to establish the boundaries and to formulate the research objective of this study. This research paper might be termed as an explanatory study since its main aim is to establish and explain the relationship between variables [33]. A quantitative methodological choice is considered within the research design. The assessment of the theoretical DR potential in the Brazilian power sector is estimated based on a set of technical assumptions and using multiple-source secondary data, mostly based on official data from the
Commented [GD3]: Um dos revisores pede para reforçar "the strengths and innovative aspects" do paper. Acrescentei esse parágrafo. Se a prof. Paula achar que ficou repetitivo, podemos retirar 
National Grid Operator (in Portuguese, ONS), Brazilian Energy Research Office (in Portuguese, EPE) and ANEEL.

The general methodological approach of this research is illustrated in Fig. 2Fig. 2 and it is mostly based on Refs. [26,30]. A five-step process is considered for estimating the current and the future DR potential for the Brazilian power sector. Therefore, the methodology is broadly divided into (1) the identification of the main processes (i.e. for the commercial and industrial sectors) and appliances (i.e. for the residential sector) suitable for DR, followed by (2) the quantification of each flexible load in terms of the overall annual electricity (TWh) and the hourly potential (GW). Then, (3) the assessment of the load profiles for each sector and region is undertaken ${ }^{3}$, followed by (4) the hourly theoretical DR potential assessment for each process ${ }^{4} \mathrm{k}$ and (5) the calculation of the overall hourly theoretical DR potential for each sector i. Finally, the analysis of the results for each year, region and application (i.e. process or appliance) is conducted. For the residential sector, a bottom-up (which distinguishes individual technologies) approach is considered to assess the theoretical DR potential whereas a top-down approach is considered to assess the theoretical DR potential for the commercial and industrial sectors. Flexible loads for commercial and industrial sectors are estimated based on their annual electricity consumption (considering 2017 as the reference year).

\footnotetext{
${ }^{3}$ Step 3 could be performed independently of the previous steps (Step 1 and 2).

${ }^{4}$ This calculation (i.e. Step 4) would also include the percentage of flexible demand for each application, as it will be further described (Section 2.4).
} 


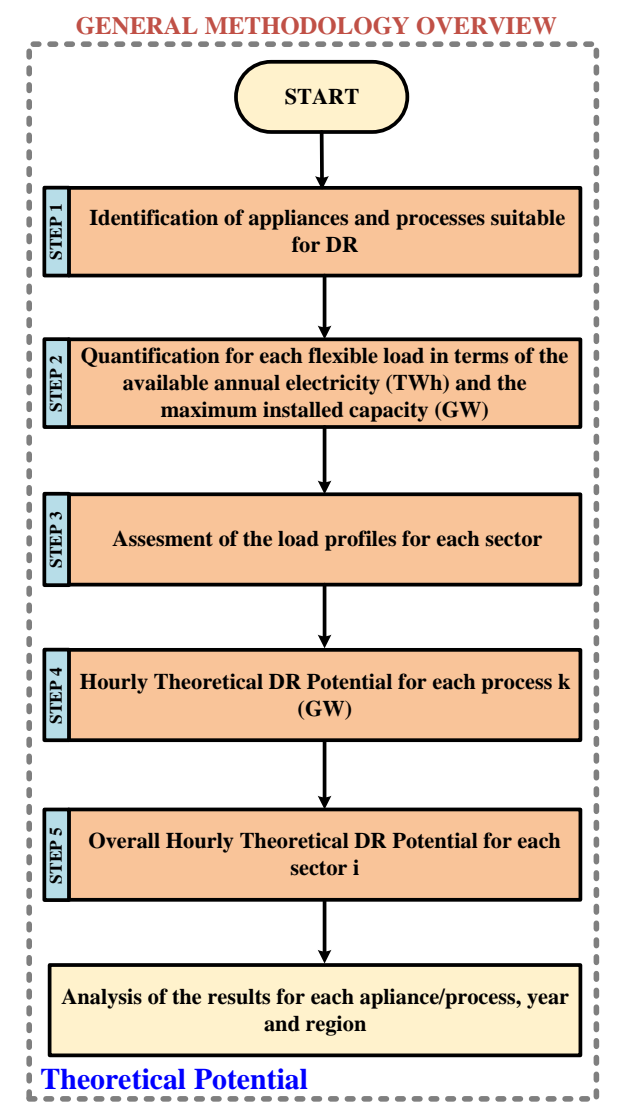

Fig. 2. The methodological approach of the research for assessing the theoretical DR potential.

Source: Adapted from $[26,30]$.

\subsection{Identification of Each Process/Appliance k Suitable for DR for Each Sector i (Step 1)}

The first step comprises the identification of suitable DR applications (i.e. loads with some degree of flexibility). Table 1Table 1 represents the main processes/appliances with some degree of DR potential, but are not limited to only these applications $[34,35]$ and would vary between countries and sectors. Other sectors are considered to be not relevant to the overall DR contribution and therefore are usually not included in the DR assessment analysis. 
Table 1: Representation of the main applications with some degree of DR potential $[34,36]$.

\begin{tabular}{ccc}
\hline Industrial & Commercial & Residential \\
\hline Paper machines & Air-conditioning & Air-conditioning \\
Non-metallic minerals & Ventilation & Washing machines \\
Non-ferrous metals & Refrigeration & Tumble dryers \\
Chemical and petrochemical & Storage water heater & Dishwashers \\
Iron \& steel & Storage heater & Water heaters \\
Wood products & Wastewater treatment & Refrigerators and freezers \\
Air Separation & Pumps in the water supply & Heating systems and electric boilers \\
Cement Mills & Cold storages & \\
Wastepaper processing & & \\
\hline
\end{tabular}

Load shedding is usually considered only for energy-intensive industries with high utilization rates such as suggested by Refs. [26,30]. Although load shedding could be also applied for commercial and residential sectors [30], this could imply high losses of comfort for these users. Therefore, only load shifting is considered for these particular sectors (i.e. commercial and residential) in traditional DR assessment analysis 5 .

\subsection{Quantification for Each Flexible Load (Step 2)}

This stage comprises the estimation in terms of energy (GWh) and maximum capacity (GW) available for DR for each process/appliance. Given the data availability and the technical differences between the applications of each sector, different approaches have been traditionally considered for the quantification of the flexible loads in each sector. For the residential sector, a bottom-up approach is considered whereas for the commercial and industrial sectors a top-down approach is traditionally employed. The estimation of the flexible load potential for each application proceeds as follows and it is mostly based on the assumptions of Refs. [26,30] and on the theoretical framework detailed in Ref. [29]. The following set of equations (1-9) allows therefore the calculation of the theoretical DR potential for each region, sector and process.

\footnotetext{
${ }^{5}$ We highlight that both load shedding and load shifting could be evaluated for other applications and it would be very useful in the case of assessing the economic DR potential since the costs for accepting load interventions would be considered in this type of analysis. Furthermore, when assessing the achievable DR potential (which also considers the load acceptance of consumers to load interventions), this aspect (i.e. possibility of using both load shedding and load shifting) should therefore be fully evaluated. However, it is beyond the scope of this study to examine these last two DR assessments (i.e. economic and achievable DR potentials) which are also considered an important issue for future research and would require the use of simulation/optimization modelling approaches.
} 


\section{Industry Sector (Energy-intensive Processes)}

For energy-intensive industries, the annual electricity consumption $\left(E_{\text {year } \_ \text {ind }}^{k}\right)$ is estimated considering the specific electricity consumption $\left(E_{\text {spec }}^{k}\right)$, production capacities $\left(A_{\text {year }}^{k}\right)$ and the capacity utilization level $\left(s_{u t i}^{k}\right)$ for each application $\mathrm{k}$ as illustrated by Eq. (1(1).

$$
E_{\text {year_ind }}^{k}=A_{\text {year }}^{k} \cdot E_{\text {spec }}^{k} \cdot s_{\text {util }}^{k}(G W h)
$$

The annual self-electricity production $\left(E_{\text {year_self_ind }}^{k}\right)$ is discounted from Eq. $(1(1)$ for each sector and year based on the available data ${ }^{6}$. Therefore, the estimated annual electricity demand $\left(E_{\text {total }_{-} \text {year }_{-} \text {ind }}\right)$ for each energy-intensive industrial process can be calculated according to Eq. $(2(2)$ for the reference year and for the future years.

$$
E_{\text {total_year_ind }}^{k}=E_{\text {year_ind }}^{k}-E_{\text {year_self_ind }}^{k}(G W h)
$$

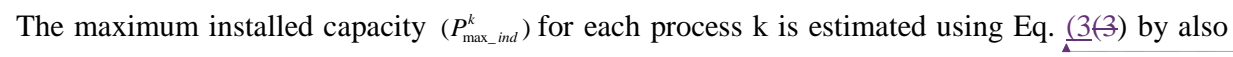
taking into account the revision outages $\left(f_{\text {rev }}^{k}\right)$ and the number of hours in a year $\left(N_{h_{-} \text {year }}\right)$.

$$
P_{\text {max_ind }}^{k}=\frac{E_{\text {year_ind }}^{k}}{N_{h_{-} \text {year }} \cdot\left(1-f_{\text {rev }}^{k}\right) \cdot s_{\text {util }}^{k}}(G W)
$$

\section{Commercial Sector}

The data available for the commercial sector is traditionally much more restricted than for the industrial sector. For this reason, the annual electricity consumption available for DR $\left(E_{\text {year } \_ \text {com }}^{k}\right)$ is

${ }^{6}$ In our assessment, the data was extracted from Ref. [9]. 
broadly estimated using the combination of each commercial individual process demand $\left(E_{c o m}^{k}\right)$ with its respective average demand share $\left(s_{c o m}^{k}\right)$ according to Eq. (4(-4).

Formatted: Font: $12 \mathrm{pt}$

$$
E_{\text {year_com }}^{k}=E_{\text {com }}^{k} \cdot s_{\text {com }}^{k}(G W h)
$$

The maximum installed capacity is estimated using Eq. (5(5) which also considers the number of

\section{Formatted: Font: $12 \mathrm{pt}$} full load hours $\left(n_{F L H}^{k}\right)$ in a year for each process $\mathrm{k}$.

$$
P_{\text {max } \_ \text {com }}^{k}=\frac{E_{\text {year_com }}^{k}}{n_{F L H}^{k}}(G W)
$$

\section{Residential Sector}

The annual electricity consumption $\left(E_{\text {year_res }}^{k}\right)$ for those appliances which offer some degree of flexibility for the residential sector is estimated applying Eq. (6(6) which considers the market Formatted: Font: $12 \mathrm{pt}$ penetration rate of each appliance $\left(f_{e q}^{k}\right)$, the number of households $\left(n_{\text {house }}\right)$ and the specific electricity consumption of each appliance $\left(E_{\text {unit }}^{k}\right)$.

$$
E_{\text {year_res }}^{k}=n_{\text {house }} \cdot f_{e q}^{k} \cdot E_{\text {unit }}^{k}(G W h)
$$

The specific capacity of each appliance $\left(P_{\text {unit }}^{k}\right)$ is also considered for the estimation of the total installed capacity of each appliance category $\left(P_{\text {max }_{-} \text {res }}^{k}\right)$ and it can be calculated by using Eq. (7) $(7)$.

Formatted: Font: $12 \mathrm{pt}$ 


\subsection{Load Profiles for Each Process (Step 3)}

The temporal availability of DR is taken into account through the identification of typical daily load profiles. Due to the lack of measurements, typical demand load patterns are considered based on available literature. The load profiles for the residential sector were estimated based on a tool developed by the National Electricity Conservation Program (in Portuguese, PROCEL) known as Information System on Possession and Habits of Consumption (in Portuguese, SINPHA). It is worth mentioning that the overall potential of the flexible demands (primarily for the residential sector) is highly dependent on the appliances characteristics (i.e. type, power, efficiency and rate of each equipment) and also on the pattern of consumption of these appliances which are affected mostly by the per capita income and the willingness to use more efficient technologies in the future [9]. Due to data scarcity regarding the load profiles for the commercial and industrial sectors, it is considered a typical load curve for these processes. For energy-intensive industries, due to both the huge heterogeneity of processes and its high utilization rates, a constant load is used during the year such as considered by Refs. [26,30].

The use of daily, weekly and/or seasonal load profiles for each application would be considered when there is enough data availability [34,36]. Load profiles for the Brazilian power sector are restricted to average values. For this reason, we do not consider differentiation on load profiles across seasons and years. However, a lively discussion is further presented in order to better understand the main seasonal implications by comparing the estimated theoretical DR potential with metered data from typical load profiles of the power system for extreme seasons (e.g. winter and summer). The data used for the load profiles of each sector are displayed in Table A.1 (Appendix A). Although the probable non-linear and time-varying characteristics of load profiles in the future, to date, there is no specific and available data regarding future end-use load profiles for the Brazilian power sector. Therefore, in this research paper the load profiles for all DR processes/appliances remain unchanged for the estimation of the flexibility potential in future years such as considered in Refs. [26,30]. 


\subsection{Hourly Theoretical DR Potential for Each Application and Sector (Step 4 and Step 5)}

The hourly theoretical load flexibility potential for each application (GW) is estimated based on the combination of the annual electricity demand with the load profile $\left(D_{\text {profile }}^{k}\right)$ and also by taking into account the number of full load hours in a year $\left(n_{F L H}^{k}\right)$ according to Eq. $\underline{(8}(8)$.

$$
E_{\text {hourly }}^{k}=\frac{E_{\text {year }}^{k} \cdot D_{\text {profile }}^{k}}{n_{F L H}^{k}}(G W)
$$

The flexible demand percentage for each application $\left(F D^{k}\right)$ would also be considered to estimate the overall hourly theoretical DR potential for each process k. Therefore, the sum (for each hour) for all applications across all sectors will comprise the overall flexibility potential of the power system under evaluation as described by Eq. $\underline{(9(9)}$.

$$
E_{\text {hourly }(i)}^{k}=\sum_{k=1}^{N}\left(E_{\text {hourly }}^{k} \cdot F D^{k}\right) \forall k, y(G W h)
$$

\section{Results and Discussion}

This section will provide the results of the assessment of the DR potential for each sector and year (up to 2050) for the specific case of the Brazilian power system following the methodology described in Section 2. The DR potential is assessed considering both load shedding and load shifting, depending on the application. The selection of the main applications with some degree ${ }^{7}$ of DR potential for the specific case of Brazil was based on data presented in Table 1Table 1. The specific applications selected to contribute to the overall DR potential are presented in Table 2Table 2.

Table 2: DR applications selected to be considered in this study.

\begin{tabular}{|c|c|c|c|}
\hline Energy-Intensive Industries & DR Action & Commercial & DR Action \\
\hline Bauxite & Shedding & Air-conditioning/ cooling & Shifting \\
\hline Alumina & Shedding & Direct Heating & Shifting \\
\hline Primary Aluminum & Shedding & Storage water heater & Shifting \\
\hline Iron and Steel & Shedding & Residential & DR Action \\
\hline
\end{tabular}

\footnotetext{
${ }^{7}$ The suitable DR applications should be selected based on a qualitative evaluation of each process/appliance [35] which mostly includes the availability, storability and controllability analysis for each application [46]. These characteristics are then correlated with the shed-ability and shift-ability of each application.
}

Formatted: Font: $12 \mathrm{pt}$

Formatted: Font: $12 \mathrm{pt}$

Formatted: Font: $12 \mathrm{pt}$ 


\begin{tabular}{|c|c|c|c|}
\hline Ferroalloys & Shedding & Freezer & Shifting \\
\hline Soda & Shifting & Refrigerator & Shifting \\
\hline Petrochemical & Shifting & Washing machine & Shifting \\
\hline Cellulose & Shifting & Laundry dryers & Shifting \\
\hline Paper Machines & Shifting & Dishwashers & Shifting \\
\hline Cement mills & Shifting & Air Conditioning & Shifting \\
\hline
\end{tabular}

The projected number of households (million), market penetration rate (\%) and specific energy consumption (kWh) for years 2017, 2020, 2030, 2040 and 2050 are presented in Table 3Table 3, Table 4Table 4 and Table 5Table 5, respectively. The data presented in Table 3Table 3, Table 4Table 4 and Table 5 Fable 5 was linearly extrapolated when no specific data was available between periods. The projected number of households between 2017 and 2027 was retrieved from Ref. [37] and for the remaining years (2030 - 2050) based on Ref. [9]. Data for each market penetration rate was retrieved from different sources such as illustrated in Table 4Table 4. Due to data scarcity, the market penetration rate for the laundry dryers and dishwashers were established by the authors based on both the available literature and authors' expertise. The specific energy consumption for each appliance (Table 5Fable 5) was estimated based on Ref. [36] and Ref. [37]. Other important data for the industrial and commercial sectors considered in this study are illustrated in Table 6Fable 6.

Table 3: Projected Number of Households (Million).

\begin{tabular}{|l|c|c|c|c|c|c|}
\hline Region & $\mathbf{2 0 1 7}$ & $\mathbf{2 0 2 0}$ & $\mathbf{2 0 3 0}$ & $\mathbf{2 0 4 0}$ & $\mathbf{2 0 5 0}$ & Reference \\
\hline NE & 18.3 & 19.3 & 22.1 & 24.4 & 26.7 & {$[9,37]$} \\
\hline NO & 6.1 & 6.4 & 7.3 & 8.1 & 8.9 & {$[9,37]$} \\
\hline SE/CO & 33.6 & 35.3 & 40.5 & 44.7 & 48.9 & {$[9,37]$} \\
\hline NO & 9.6 & 10.1 & 11.6 & 12.8 & 14.0 & {$[9,37]$} \\
\hline Total & $\mathbf{6 7 . 7}$ & $\mathbf{7 1 . 1}$ & $\mathbf{8 1 . 5}$ & $\mathbf{9 0 . 0}$ & $\mathbf{9 8 . 5}$ & - \\
\hline
\end{tabular}

Table 4: Market Penetration Rate (\%).

\begin{tabular}{|l|c|c|c|c|c|c|}
\hline \multicolumn{1}{|c|}{ Equipment } & $\mathbf{2 0 1 7}$ & $\mathbf{2 0 2 0}$ & $\mathbf{2 0 3 0}$ & $\mathbf{2 0 4 0}$ & $\mathbf{2 0 5 0}$ & Reference \\
\hline Freezer & $18.0 \%$ & $15.4 \%$ & $14.6 \%$ & $13.3 \%$ & $12.0 \%$ & {$[9]$} \\
\hline Refrigerator & $110.0 \%$ & $110.6 \%$ & $112.0 \%$ & $112.0 \%$ & $112.0 \%$ & {$[37]$} \\
\hline Washing Machine & $69.0 \%$ & $74.4 \%$ & $81.0 \%$ & $87.5 \%$ & $94.0 \%$ & {$[9]$} \\
\hline Laundry Dryers & $6.9 \%$ & $7.2 \%$ & $8.2 \%$ & $9.4 \%$ & $10.8 \%$ & - \\
\hline Dishwashers & $2.0 \%$ & $2.1 \%$ & $2.4 \%$ & $2.7 \%$ & $3.1 \%$ & - \\
\hline Air Conditioning & $42.0 \%$ & $46.2 \%$ & $60.7 \%$ & $62.8 \%$ & $65.0 \%$ & {$[9]$} \\
\hline
\end{tabular}

Table 5: Specific Energy Consumption (kWh/Equipment).

\begin{tabular}{|l|c|c|c|c|c|c|}
\hline \multicolumn{1}{|c|}{ Equipment } & $\mathbf{2 0 1 7}$ & $\mathbf{2 0 2 0}$ & $\mathbf{2 0 3 0}$ & $\mathbf{2 0 4 0}$ & $\mathbf{2 0 5 0}$ & Reference \\
\hline Freezer & 473 & 459 & 413 & 372 & 335 & {$[37]$} \\
\hline Refrigerator & 324 & 314 & 284 & 257 & 233 & {$[37]$} \\
\hline Washing Machine & 64 & 62 & 58 & 55 & 51 & {$[37]$} \\
\hline Laundry Dryers & 308 & 314 & 335 & 357 & 381 & {$[36]$} \\
\hline Dishwashers & 272 & 277 & 296 & 315 & 336 & {$[36]$} \\
\hline Air Conditioning & 654 & 640 & 595 & 554 & 515 & {$[37]$} \\
\hline
\end{tabular}


Table 6: Other input data.

\begin{tabular}{|c|c|}
\hline Industrial Sector & Value \\
\hline Revision outages (\%) & $5 \%$ \\
\hline Capacity utilization level (\%) & $90 \%$ \\
\hline Number of hours in a year & 8760 \\
\hline Flexible share (\%) & $100 \%$ \\
\hline Commercial Sector & Value \\
\hline Annual Growth (\%) - 2017-2020 & $5.1 \%$ \\
\hline Annual Growth (\%) - 2020-2030 & $5.2 \%$ \\
\hline Annual Growth (\%) - 2030-2040 & $4.4 \%$ \\
\hline Annual Growth (\%) - 2040-2050 & $4.5 \%$ \\
\hline Number of full load hours & 5840 \\
\hline
\end{tabular}

\subsection{Flexible Load Potential in the Industrial Sector}

The specific electricity consumption $(\mathrm{kWh} / \mathrm{t})$ and the yearly production $(\mathrm{Mt})^{8}$ for each energyintensive industrial process were estimated based on different data sources as presented in Table 7Fable 7.

Table 7: Specific electricity consumption $(\mathrm{kWh} / \mathrm{t})$ and yearly production $(\mathrm{Mt})$ for each energy-intensive process.

\begin{tabular}{|l|c|c|c|c|c|c|c|c|c|c|c|}
\hline \multicolumn{1}{|c|}{ Process } & \multicolumn{2}{|c|}{$\mathbf{2 0 1 7}$} & \multicolumn{2}{c|}{$\mathbf{2 0 2 0}$} & \multicolumn{2}{c|}{$\mathbf{2 0 3 0}$} & \multicolumn{2}{c|}{$\mathbf{2 0 4 0}$} & \multicolumn{2}{c|}{$\mathbf{2 0 5 0}$} & \multirow{2}{*}{ Reference } \\
\hline & $\mathbf{k W h} / \mathbf{t}$ & $\mathbf{M t} / \mathbf{y e a r}$ & $\mathbf{k W h} / \mathbf{t}$ & $\mathbf{M t} / \mathbf{y e a r}$ & $\mathbf{k W h} / \mathbf{t}$ & $\mathbf{M t} / \mathbf{y e a r}$ & $\mathbf{k W h} / \mathbf{t}$ & $\mathbf{M t} / \mathbf{y e a r}$ & $\mathbf{k W h} / \mathbf{t}$ & $\mathbf{M t} / \mathbf{y e a r}$ & \\
\hline Bauxite & 13 & 40.0 & 13 & 42 & 12 & 55 & 12 & 67 & 12 & 81 & {$[9,38]$} \\
\hline Alumina & 290 & 11.7 & 284 & 13 & 267 & 16 & 259 & 20 & 255 & 25 & {$[9,38]$} \\
\hline Primary Aluminum & 14373 & 0.9 & 14089 & 1 & 13405 & 1 & 13099 & 1 & 12978 & 2 & {$[9,38]$} \\
\hline Iron and Steel & 505 & 38.6 & 500 & 42 & 462 & 62 & 444 & 75 & 447 & 81 & {$[9,39]$} \\
\hline Ferroalloys & 8809 & 1.0 & 8957 & 1 & 8661 & 2 & 8535 & 2 & 8480 & 2 & {$[9,39]$} \\
\hline Pellets & 48 & 46.3 & 48 & 46 & 47 & 46 & 46 & 46 & 46 & 46 & {$[9,40]$} \\
\hline Primary Copper & 1503 & 0.2 & 1476 & 0 & 1425 & 0 & 1404 & 0 & 1394 & 0 & {$[9,40]$} \\
\hline Soda & 2675 & 1.5 & 2639 & 2 & 2558 & 2 & 2515 & 3 & 2479 & 4 & {$[9,39]$} \\
\hline Petrochemical & 1552 & 3.0 & 1524 & 3 & 1490 & 5 & 1491 & 7 & 1471 & 9 & {$[9,39]$} \\
\hline Cellulose & 957 & 22.4 & 939 & 28 & 899 & 43 & 882 & 52 & 877 & 61 & {$[9,39]$} \\
\hline Paper Machines & 774 & 11.7 & 761 & 13 & 731 & 20 & 717 & 28 & 712 & 33 & {$[9,39]$} \\
\hline Cement mills & 109 & 71.1 & 107 & 72 & 101 & 106 & 97 & 137 & 93 & 131 & {$[9,39]$} \\
\hline
\end{tabular}

The results presented in Table 7Fable 7 were further divided into the four main Brazilian subsystems namely Northwest (NE), Southwest ${ }^{9}$ (SE), North (NO) and South (SO) in order to assess the regional-specific characteristics in the overall theoretical DR potential. Fig. 3 Fig. 3 illustrates the main Brazilian regions which are divided into RS, SC and PR (South); SP, MG, RJ, ES, MS, GO, DF and MT (Southwest and Midwest); BA, SE, AL, PE, PB, RN, CE. MA, PI (Northwest) and AC, RO,

\footnotetext{
${ }^{8}$ Mt stands for 'Millions of tons'.

${ }^{9}$ Technically, the Southwest (SE) subsystem comprises both Southwest and Midwest regions in Brazil (SE/CO). Therefore, along with this paper, it will be used the term SE, which would represent both subsystems SE and CO.
}

Formatted: Font: $12 \mathrm{pt}$

Formatted: Font: $12 \mathrm{pt}$ 
TO, PA, AM, AP, RR (North). This was performed based on the percentual contribution of each process in the overall electricity consumption of the industrial sector for each region according to the data retrieved from Ref. [43].

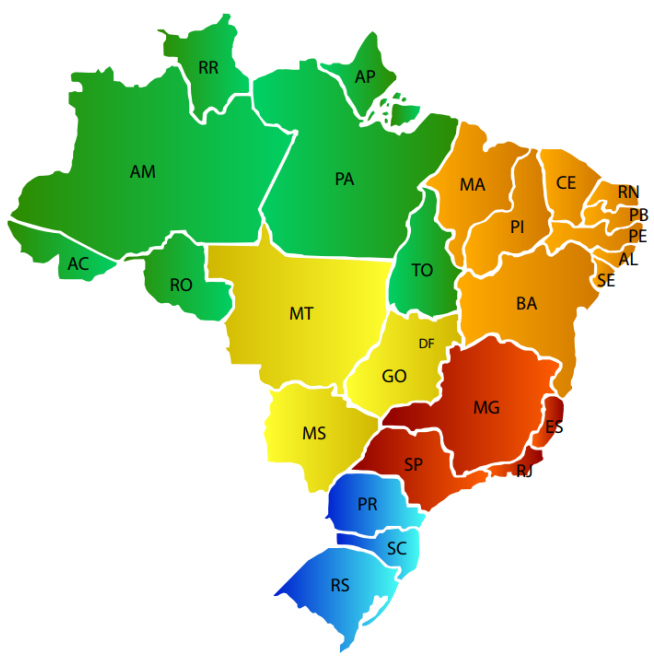

Fig. 3. Regions of the country (Brazil)

The overall DR potential (TWh) for each region and energy-intensive industrial process in 2017 and 2050 are illustrated in Fig. 4Fig. 4 and Fig. 5 Fig. 5 , respectively and it was estimated based on the set of assumptions presented in Section 2. It is worth mentioning that depending on the process, the DR potential might be categorized for load shedding or load shifting (see Section 2 for more details). However, for the sake of simplicity, the illustrations for the energy-intensive industrial processes are summed up in Fig. 4Fig. 4 and Fig. 5Fig. 5. Specifically, the overall energy shedding potential increases by $102 \%$ - from $31.2 \mathrm{TWh}$ (2017) to $63 \mathrm{TWh}$ (2050) - whereas the energy shifting potential is projected to increase $115 \%$ in the same period (from $27.8 \mathrm{TWh}$ in 2017 to $59.8 \mathrm{TWh}$ in 2050).

As can be seen from Fig. 4Fig. 4 and Fig. 5Fig. 5, the Southwest region (SE) represents the higher contribution share in the overall DR potential for the industrial sector comparatively to other regions. The North (NO) has a particular high contribution for the following processes: iron and steel, primary aluminum and ferroalloys and lower but still substantial potentials for alumina, pellets, and bauxite. The South (SO) accounts for the lowest contribution in the overall DR potential for the industrial sector (6.2 
TWh in 2017 and 16.8 TWh in 2050) comparatively to the other regions but a high load flexibility potential can be found for paper machines and cellulose in this region. The iron and steel category stands out with the highest contribution in the overall DR potential for the industrial sector along with all the period (2017-2050) increasing from 12.2 TWh in 2017 to almost $21.6 \mathrm{TWh}$ in 2050 although the highest growth rate in the period can be attributed respectively for the petrochemical and papers machines processes.

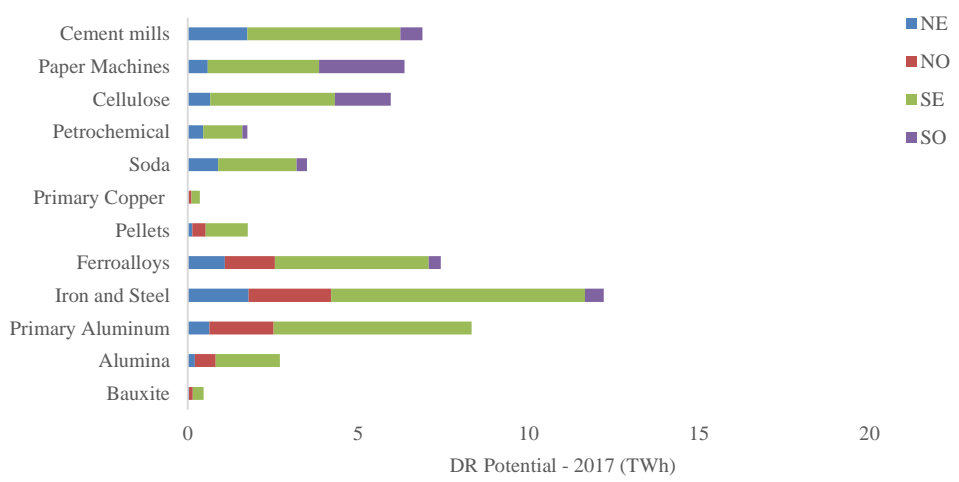

Fig. 4. DR Potential for each region and energy-intensive industrial process in 2017 (TWh).

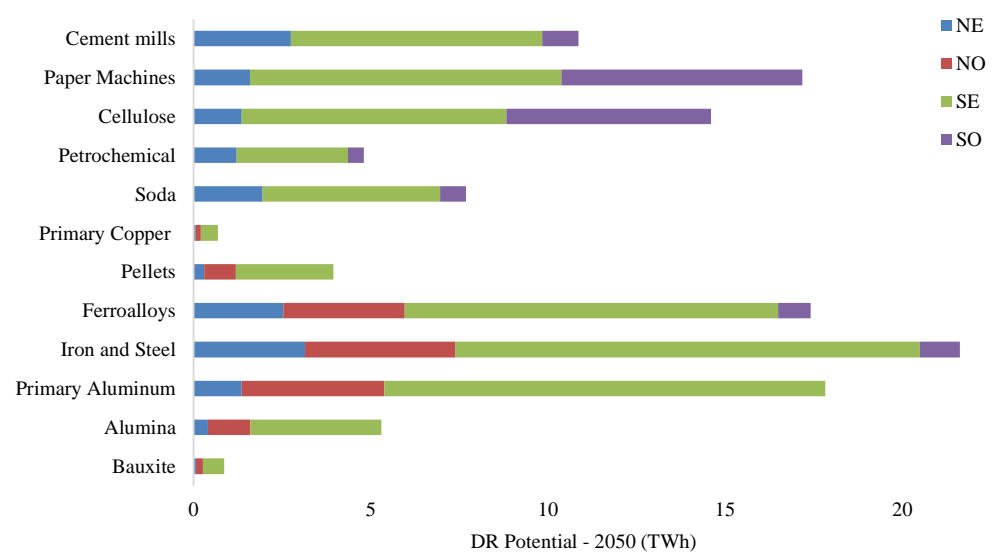

Fig. 5. DR Potential for each region and energy-intensive industrial process in 2050 (TWh). 
Further analysis illustrates the overall DR potential by region and year for energy-intensive industrial processes (Fig. 6Fig.6). What stands out, in this case, is the wide disparity between the DR potentials for each region. The Southwest (SE) represents the highest DR potential for both load shedding and load shifting. For the North (NO), a low load shifting potential can be observed during all the period (2017-2050) comparatively to its load shedding potential. The opposite occurs for the South (SO) in which the load shifting potential is substantially greater than its load shedding potential.

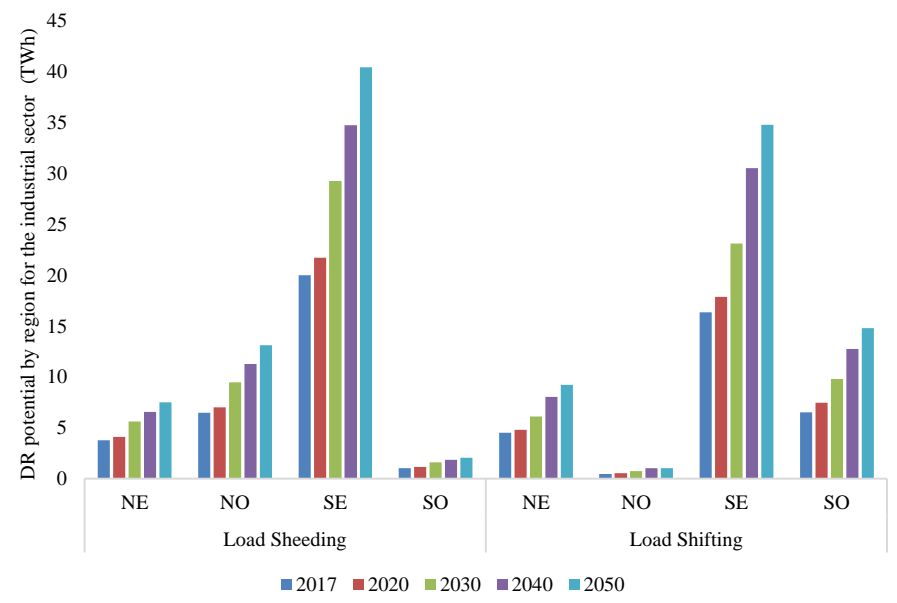

Fig. 6. Overall DR potential by region and year for energy-intensive industrial processes (TWh).

The overall DR potential (GW) for each energy-industrial process is illustrated in Fig. 7Fig. 7. Our findings suggest that the overall load flexibility potential (i.e. maximum DR capacity in GW) for energy-intensive industries would increase from 7.9 GW in 2017 to approximately $16.4 \mathrm{GW}$ in 2050 . 


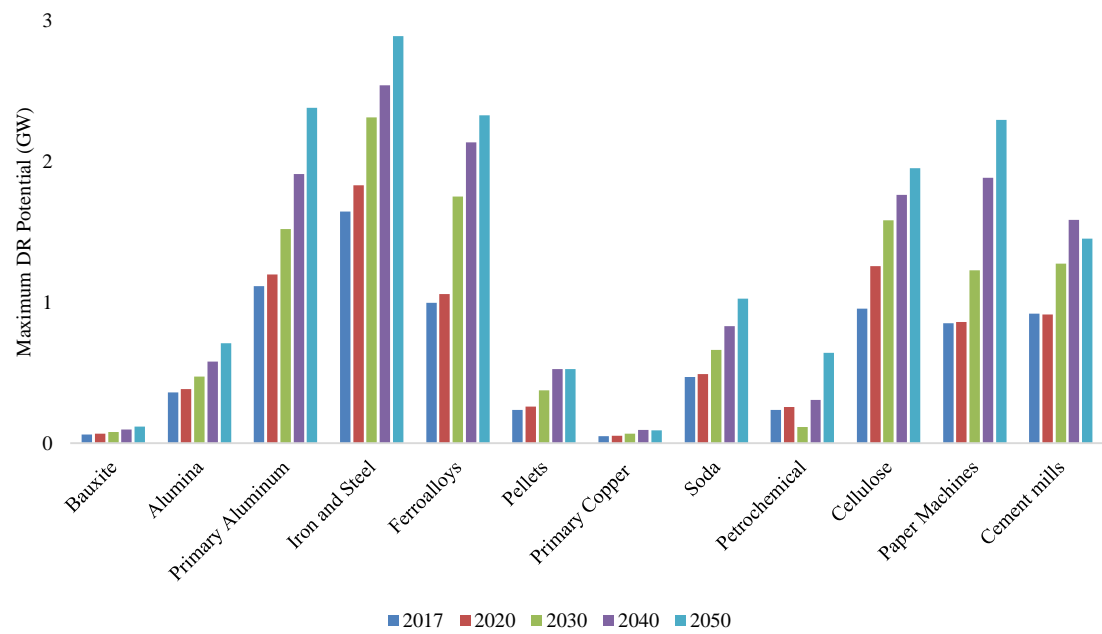

Fig. 7. Maximum DR potential for each energy-intensive industrial process (GW)

\subsection{Flexible Load Potential in the Commercial Sector}

For estimating the DR potential of the commercial sector, it is assumed that $10 \%$ (for each year) of the total electricity consumption would come from self-generation systems. Therefore, this share is discounted from the overall DR potential of the commercial sector (See Eq. (4(4)).

The overall DR potential (TWh) for each process considered suitable for DR in the commercial sector is illustrated in Fig. 8Fig. 8. According to these data, we can infer that the air-conditioning/cooling systems are responsible for the highest commercial DR potential which more than quadruple its share, increasing from 11.5 TWh in 2017 to $52.8 \mathrm{TWh}$ in 2050. Heating processes present a very limited contribution comparatively to the air-conditioning/cooling systems. However, we point out that the results for the commercial sector were based upon restricted available data and therefore the lack of detailed data in the sample adds further caution regarding the generalisability of these findings. 


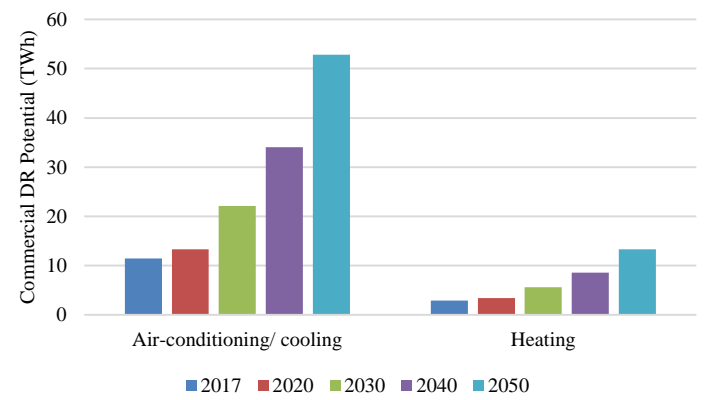

Fig. 8. Overall DR potential (energy shifting potential) for commercial processes (TWh).

The number of full load hours in a year is based on the typical workday hours (i.e. 5840 hours) for all processes in the commercial sector. Table 8 Table 8 illustrates the overall DR potential $(\mathrm{GW})$ for each process. As can be seen in Table 8Table 8, the air-conditioning/cooling systems provide the major DR potential contribution in the commercial sector.

Table 8: Commercial DR potential for each process and year $(\mathrm{GW})$.

\begin{tabular}{|l|c|c|c|c|c|}
\hline \multicolumn{1}{|c|}{ Process } & $\mathbf{2 0 1 7}$ & $\mathbf{2 0 2 0}$ & $\mathbf{2 0 3 0}$ & $\mathbf{2 0 4 0}$ & $\mathbf{2 0 5 0}$ \\
\hline Air-conditioning/cooling & 2.0 & 2.3 & 3.8 & 5.8 & 9.0 \\
\hline Heating & 0.5 & 0.6 & 1.0 & 1.5 & 2.3 \\
\hline
\end{tabular}

At this point, we highlight that the data presented in Table 8 Fable 8 consider the maximum DR

Formatted: Font: $12 \mathrm{pt}$ capacity for each process. This implies that the hourly temporal availability ${ }^{10}$ would be generally lower than the data presented in Table 8 Table 8. Fig. 9Fig. 9 illustrates the typical DR daily availability profile (GW) for each region for the commercial sector (left axis) and the typical daily load curve of the interconnected power system (GW) in the right axis for the year 2017. It can be observed in Fig. 9Fig. 9 that the DR potential is estimated to vary between $0.1 \mathrm{GW}$ to $1.6 \mathrm{GW}$ across a typical day which corresponds respectively to $5 \%$ and $67 \%$ of the estimated maximum DR capacity presented in Table 8Table 8 (for the year 2017). The results illustrated in Fig. 9Fig. 9 clearly indicate the major contribution of air-conditioning and cooling systems (representing more than half of the DR potential

${ }^{10}$ This conclusion is also valid for the other sectors evaluated (i.e., residential and industrial) 
of the commercial sector) which is mostly evidenced during the day (especially from 8 a.m. to 18 p.m.). This result is somewhat counterintuitive since the higher DR potential for the commercial sector occurs during the typical workday hours. A very limited DR potential comes from the heating processes. As expected, due to the limited commercial activity at night, the DR potential at this period is very limited. We also highlight that for the commercial sector the DR availability best matches the daily load curve of the power system (see the right axis of Fig. 9Fig. 9). These results provide further support for the hypothesis that the commercial sector will develop a key role in offering more valuable load flexibility potential comparatively to other sectors (e.g. the industrial and residential sectors).

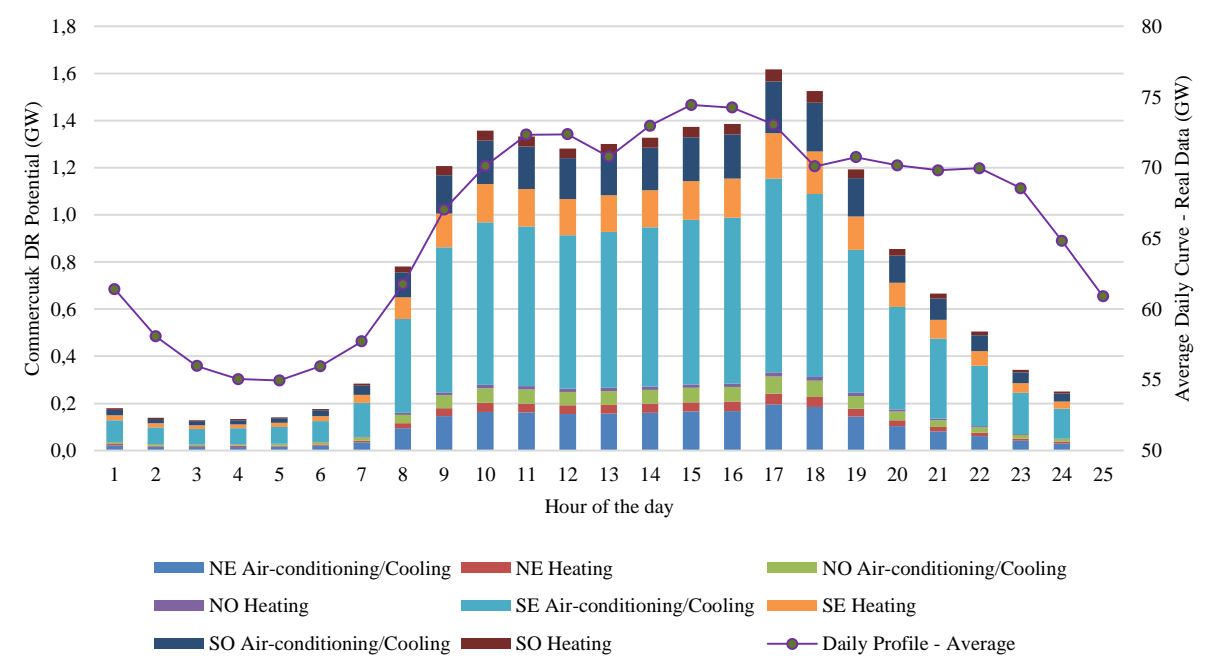

Fig. 9. Overall DR potential for each commercial process (left axis) and the average daily load curve of the interconnected power system (right axis) (in GW for a typical day of 2017).

\subsection{Flexible Load Potential in the Residential Sector}

This section attempts to assess the load flexibility potential for the residential sector for each appliance, region and year. The overall DR potential (TWh) for selected years and for each region is illustrated in Table 9Table 9. Clearly, the highest and the lowest load flexibility potential are located respectively in the Southwest (SE) and North (NO) regions for all the years. 
Table 9: Residential DR potential (TWh) for each region and year.

\begin{tabular}{|c|c|c|c|c|c|c|}
\hline Region/year & $\mathbf{2 0 1 7}$ & $\mathbf{2 0 2 0}$ & $\mathbf{2 0 3 0}$ & $\mathbf{2 0 4 0}$ & $\mathbf{2 0 5 0}$ & \% of each region \\
\hline NE & 14 & 15 & 19 & 20 & 22 & $27.1 \%$ \\
\hline NO & 5 & 5 & 6 & 7 & 7 & $9.0 \%$ \\
\hline SE & 26 & 28 & 34 & 37 & 40 & $49.7 \%$ \\
\hline SO & 8 & 8 & 10 & 10 & 11 & $14.2 \%$ \\
\hline Total & $\mathbf{5 3}$ & $\mathbf{5 6}$ & $\mathbf{6 9}$ & $\mathbf{7 4}$ & $\mathbf{8 1}$ & $100.0 \%$ \\
\hline
\end{tabular}

Fig. 10Fig. 10 illustrates the hourly contribution of each region in the overall DR potential (GW)

considering a typical day of 2017. As expected, a significantly higher DR potential can also be noted for the Southwest (SE) region. However, contrarily to the industrial sector, it is evident the higher DR contribution of the Northwest (NE) in the overall load flexibility potential for the residential sector. According to these data, we can also infer that for a typical day, the highest DR potential for the residential sector would be nearly $5.5 \mathrm{GW}$ (22 p.m.) for the entire power system.

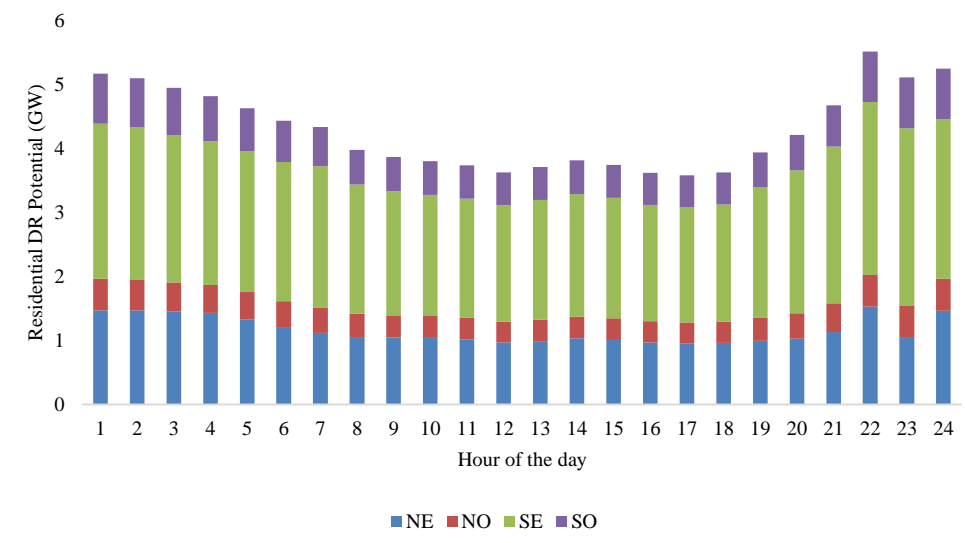

Fig. 10. Overall hourly DR Potential for each region in the residential sector - 2017 (GW).

The average theoretical hourly DR potential of each appliance of the residential sector is illustrated in Fig. 11Fig. 11 for a typical day (left axis). 


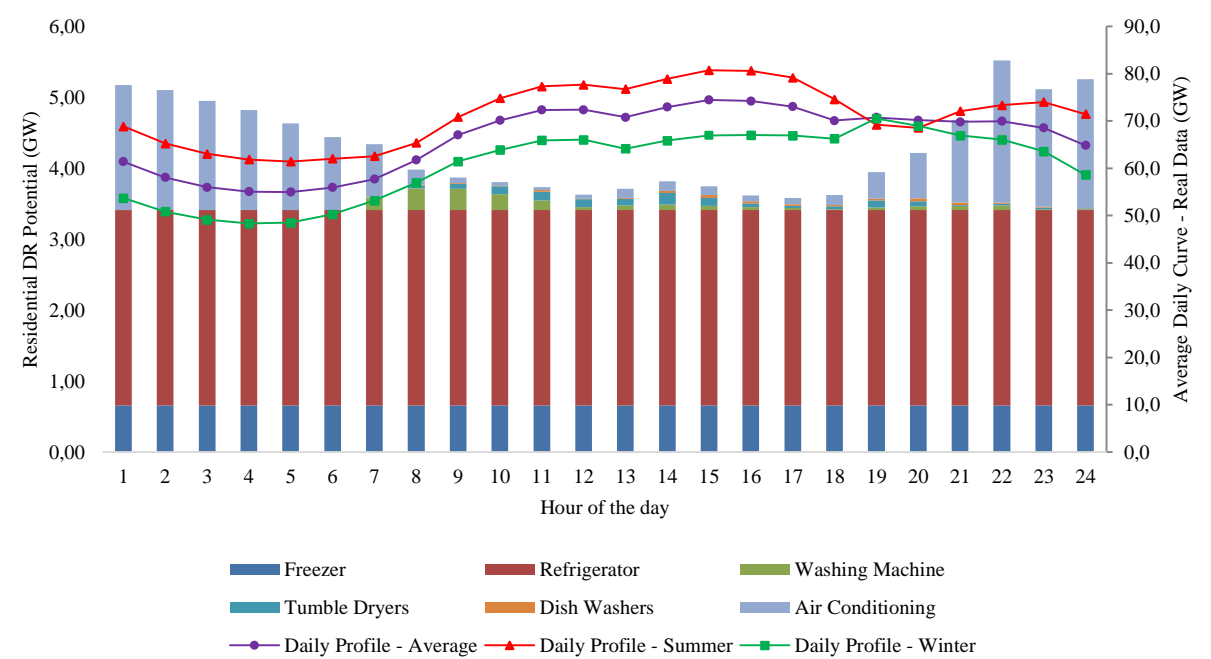

Fig. 11. Overall hourly DR potential for each appliance in the residential sector (left axis) and the average daily load curve of the interconnected power system (right axis) (in GW for 2017).

The results illustrated in Fig. 11Fig. 11 clearly indicate that the major contribution to the overall load flexibility potential of the residential sector comes particularly from the use of refrigerators (with a constant load factor during all day). These results are similar to those reported by Ref. [30] in which the refrigerator represented the highest DR potential for the residential sector in the power system evaluated ${ }^{11}$. However, one of the most marked differences between our results and the ones from Ref. [30] relates to the air-conditioning contribution to the overall DR potential. For our case, this appliance is projected to have a huge contribution in the overall DR potential (with a particular higher contribution between 22 p.m. and 6 a.m.) whereas, in the case of the German power system, this appliance represents a very limited DR contribution. These different results are likely to be related to the diverse climate conditions of each country. Our results seem to be consistent with the strategic energy plan of Brazil [37] which projected that air-conditioning systems are considered to be the main contributor to the increase in electricity consumption in the residential sector (with a rate of growth of

${ }^{11}$ Ref. [30] assessed the theoretical DR potential for the German power system. 
$4.5 \%$ between 2017 and 2027) and consequently the overall flexibility potential of this appliance would also increase in the future. This aspect can be mostly explained by the growth rate of household per capita income, which would potentialize the selling of this appliance (i.e. the market penetration rate) in the Brazilian electricity market. On the other side, it is worth mentioning that even considering a decrease in the specific electricity consumption (kWh) of air-conditioners (decreasing ${ }^{12}$ near to $21 \%$ between 2017 and 2050), this type of appliance would still appear as one of the most important drivers to the overall load flexibility potential in the future.

It is evidently clear from the findings (see Fig. 11Fig. 14) that the washing equipment has only a small contribution in the overall DR potential which mostly occurs during the day hours. In this last category, the washing machines represent the highest contribution followed by the tumble dryers and in a very limited extent appears the dishwashers. The small contribution of both tumble dryers and dishwashers are mostly related to its low penetration in the Brazilian electricity market even in future years.

So far, our analyses have focused on sectoral and regional DR analyses. It would be useful at this stage moving on to consider the relationship between the typical daily load curve profiles of the power system (i.e. for extreme seasons) considering real data extracted from the National Grid Operator [16] with the DR potential for each hour of the day. Due to the availability of data, our analysis does not focus on the contribution of DR across seasons, since no specific data (across all sectors) is available in the country. However, a set of analyses can be inferred from the results. For instance, it can be seen analyzing the right axis of Fig. 11Fig. 14 (which represents the typical daily load curve profile of the entire power system for winter, summer and the average values across all seasons) similar general load daily profiles for all seasons (although different numerical contributions occur across each season). As stated previously, in a typical summer day there is a higher demand for the interconnected power system (comparatively to a typical winter day). Therefore, our results provide further support for the hypothesis that the DR potential would also be larger during summer times (for the entire

\footnotetext{
${ }^{12}$ This decrease is mostly driven by the new normative resolutions proposed by the Brazilian government which established minimum energy efficiency rates for air-conditioners [47].
} 
interconnected power system ${ }^{13}$ ). This higher contribution in the overall DR potential during summer is supposed to come from the air-conditioners ${ }^{14}$ (mostly from the residential sector), although further research is required to confirm this finding using more detailed data.

Analyzing Fig. 11Fig. 11 it is also possible to address whether or not the residential DR potential is available when the power system mostly need. The most striking result to emerge from the data presented in Fig. 11Fig. 14 is that during times of high electricity consumption (e.g. 15 p.m. and 16 p.m. $)^{15}$ the residential DR potential is much lower than in times of reduced load (e.g. during the night). Therefore, the highest DR potential occurs during off-peak times and a small share of this potential is available during on-peak times. Further analysis of the data reveals that refrigeration and air-conditioner systems are the flexible loads which mostly contributes to the high DR potential at this time. Since the refrigerator has a constant load profile, it can be inferred that the higher DR potential for the residential sector at this time (22 p.m.) could be specifically attributed to the higher contribution of this equipment from 22.p.m. until the beginning of the morning. The lowest and the highest DR potential for the residential sector is estimated to occur respectively at noon $(3.6 \mathrm{GW})$ and at 22 p.m. $(5.5 \mathrm{GW})$. Our results are in line with those of previous studies such as the ones reported by Ref. [26] which addressed specifically the relationship between the time dependency of DR resources with the typical load profiles for the German power system and concluded that DR potential is not necessarily available during on-peak times.

Analyzing the data illustrated in Fig. 11Fig. 11, we can also infer that for a typical summer day, the load is significantly higher than in a typical winter day during almost all day, except for a few periods (i.e. 18 p.m. to 20 p.m.). Although it is well-known that the higher residential consumption occurs at this period (i.e. 18 p.m. to 20 p.m.), this load profile pattern can be mostly explained because of the industrial

\footnotetext{
${ }^{13}$ The generalisability of these results considering each region is subject to certain limitations, due to data availability of the typical daily load profiles for each appliance and region.

${ }^{14}$ See for example the real daily curve during 22 p.m. and 06 a.m. (Fig. 11Fig. 9). It can be noted that during this period, the typical summer load curve is significantly higher than the winter load curve and it is therefore likely that such connections exist mostly because of the use of air-conditioners in the residential sector.

${ }^{15}$ It is important to note that the maximum demand in the Brazilian power system has occurred at different times depending on the month of the year. In general, the maximum demand has occurred between 14 p.m. and 16 p.m. or between 18 p.m. and 19 p.m. This maximum demand also varies according to each subsystem.
} 
consumers switch part of their electricity consumption to self-generation systems due to the high costs for producing electricity during this period (i.e. 18 p.m. to 21 p.m.).

The main aim of our investigation at this point is to highlight the particularities between regions within the country. Fig. 12Fig. 12 and Fig. 13Fig. 13 illustrates the overall load profile for two particular regions (i.e. SE and NO) retrieved from metered data from the National Grid Operator [16] for a typical winter and summer day (right axis) and the respectively estimated theoretical DR potential for the residential sector (left axis) for SE and NO regions respectively. According to the data illustrated in Fig. 12Fig. 12 and Fig. 13Fig. 13, we can identify similar load profile curves for both regions (i.e. SE and NO) across winter and summer seasons. Particularly for the Southwest (SE), the numerical load value (considering a typical day) diverges significantly in a typical summer day comparatively to a typical winter day. This behavior, however, cannot be identified for the North subsystem. Therefore, we highlight the importance of assessing the theoretical DR potentials across sectors considering the particularities of each region within the country. Due to its continental dimensions, the climate conditions strongly vary between regions which together with other asymmetric characteristics make the regional analysis of the load flexibility potential particularly important. This could lead to possible synergies between subsystems across the country. Future assessments considering both the DR potential of each region together with transmission capacities analyses, for example, would potentialize the synergies between these sources of flexibility and consequently it would possibly support the integration of higher levels of VRE into the power system. 


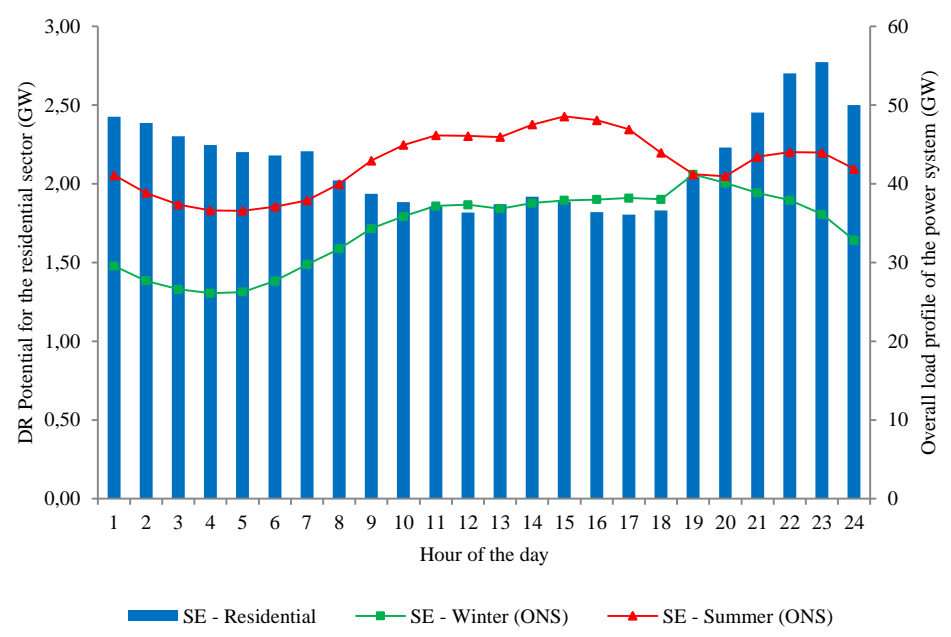

Fig. 12. Overall load profile of the power system for winter and summer (right axis) and DR potential for the residential sector (left axis) for the Southwest (SE) - 2017.

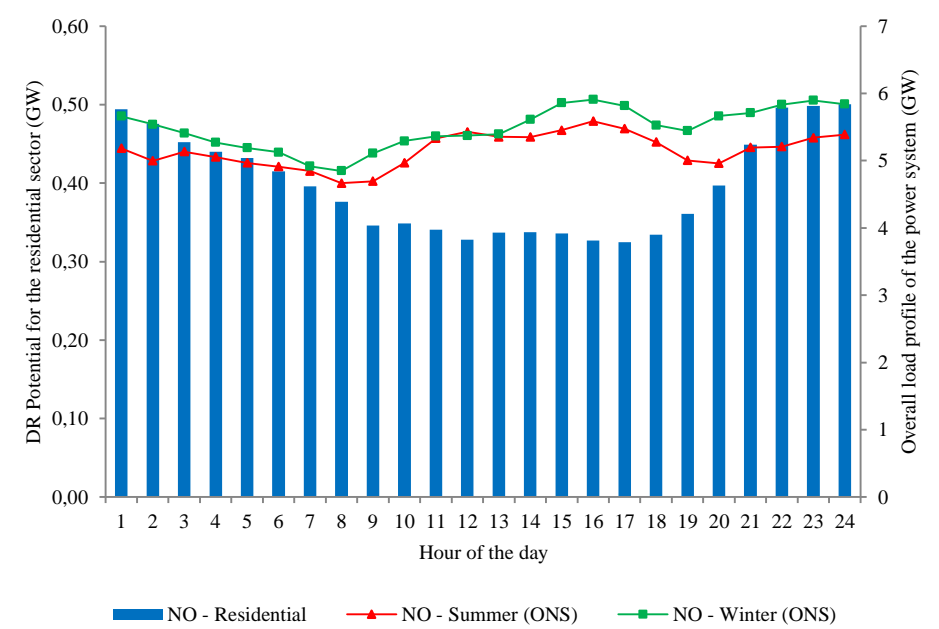

Fig. 13. Overall load profile of the power system for winter and summer (right axis) and DR potential for the residential sector (left axis) for the North (NO) - 2017.

Fig. 14Fig. 14 illustrates the overall DR potential for the residential sector in 2050 based on the data extrapolation. As no changes in the load profile were considered for future years, the load profile is identical of 2017. However, a higher DR potential can be observed mostly driven by both the increasing population and the market penetration growth of each appliance. A further issue that emerged from 
these data regards the steadily decreasing contribution share of freezers for future years. This aspect is supported by Ref. [37] which associate this reduction to the changes in the habits of consumption of households, occurred particularly in the last decades in the country but also because of the new normative resolution (see [44]) which established minimum energy efficiency rates for refrigerators and freezers.

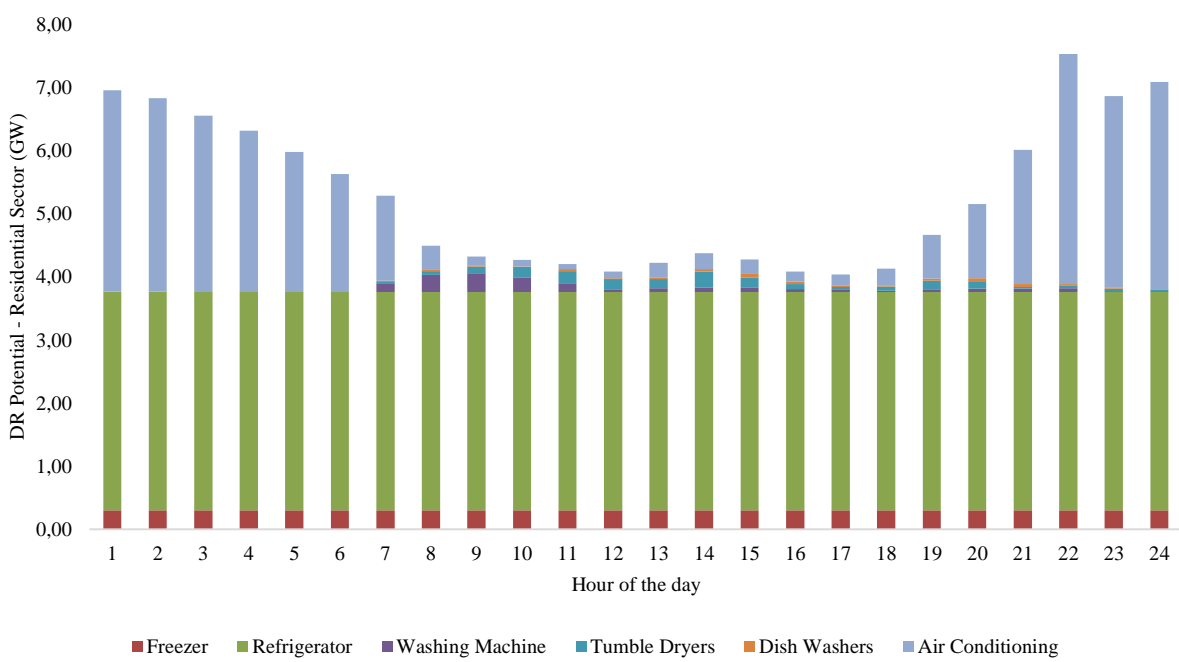

Fig. 14. Overall Hourly DR Potential for each Appliance in the Residential Sector - 2050 (GW).

\subsection{Flexible Load Potential Across All Sectors}

This section will attempt to assess the general findings of this research across all sectors evaluated. Firstly, the sectoral share of the overall load flexibility potential for the reference year (2017) and for future years (2020, 2030, 2040 and 2050) is evaluated as illustrated in Fig. 15Fig. 15. It can be seen from the data in Fig. 15Fig. 15 a slight decrease in the residential contribution share (for all regions) in the overall DR potential. This occurs mostly because of the markedly higher rates for the commercial sector and with a lower but still significant high growth rate for the industrial sector. 


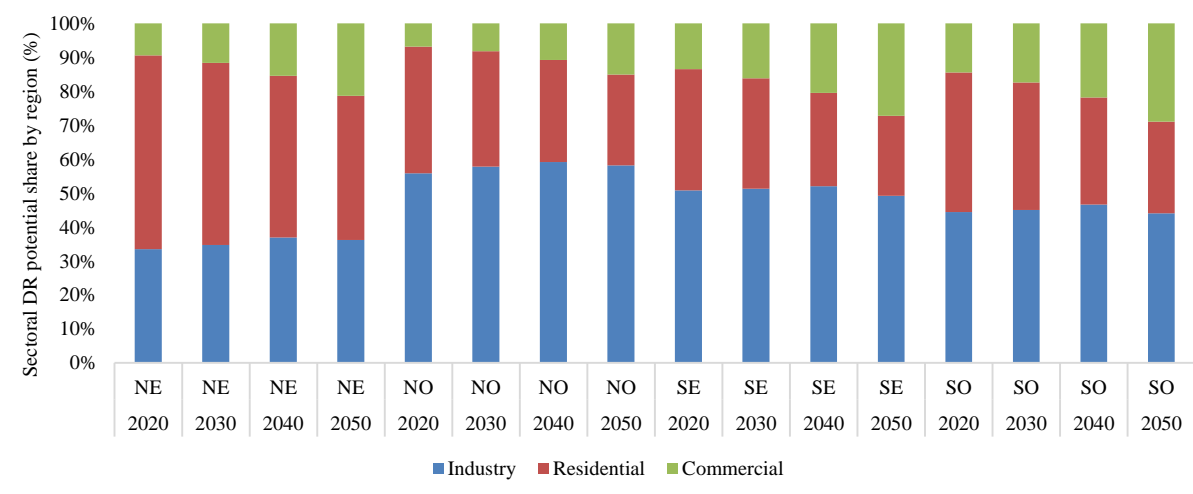

Fig. 15. Sectoral share of the overall load flexibility potential (\%).

For the sake of clarity, it would be useful at this stage to consider the comparison between the estimated DR potential assessed in this paper (see Fig. 15Fig. 15) with the respective regional share in the overall electricity consumption of the country (Fig. 16Fig. 16) projected by the Brazilian Energy Research Office for future years [9]. Analyzing Fig. 16Fig. 16, it can be seen that the sectoral share in the overall electricity consumption ${ }^{16}$ is projected to change over the period analyzed [9]. In 2020, for example, the industrial sector is projected to be responsible for the highest share in the overall electricity consumption (45.8\%) followed by the residential (24.1\%) and commercial sectors (17.2\%). Ref. [9] found a tendency of a steadily decreasing rate for the share in the overall electricity consumption for the residential sector, particular between 2030 and 2050, whereas a steadily decrease in the contribution share for the industrial sector can be verified for the future years. What stands out is the markedly increasing electricity consumption share in the commercial sector, increasing from $17.2 \%$ in 2017 to $26.6 \%$ in 2050 . Therefore, the commercial sector would exceed the share of the residential sector by 2040 as illustrated in Fig. 16Fig. 16 (regarding the overall electricity consumption).

On the other hand, our results suggest a different pattern in the total share for each sector regarding the overall DR potential, which also varies from region to region such as illustrated in Fig. 15Fig. 15. The

| ${ }^{16}$ Note that Fig. 16Fig. 14 does not refer to any aspects of DR potential, but it denotes the estimated sectoral share in the overall electricity consumption assessed by the Brazilian Energy Research Office for the Brazilian power system for future years [9]. 
high growth rate projected for the DR potential in the commercial sector is not sufficient to surpass the residential load flexibility potential in 2040 , for instance, although the contribution share of commercial sector in the overall DR potential steadily increases along with the years (see Fig. 15Fig. 15). Furthermore, it can be seen from the data in Fig. 15Fig. 15 that for the North (NO), Southwest (SE) and South (SO) the overall DR potential follows the same order across sectors, i.e., the industry with the highest DR potential, followed by the residential and the commercial sectors ${ }^{17}$. However, for the Northwest (NE), a different pattern can be observed. For this case, the residential sector contributes significantly more than the industrial sector to the overall load flexibility potential for the entire period (2020 2050) and this can be mostly explained by the low energy-intensive industrial activities in this region.

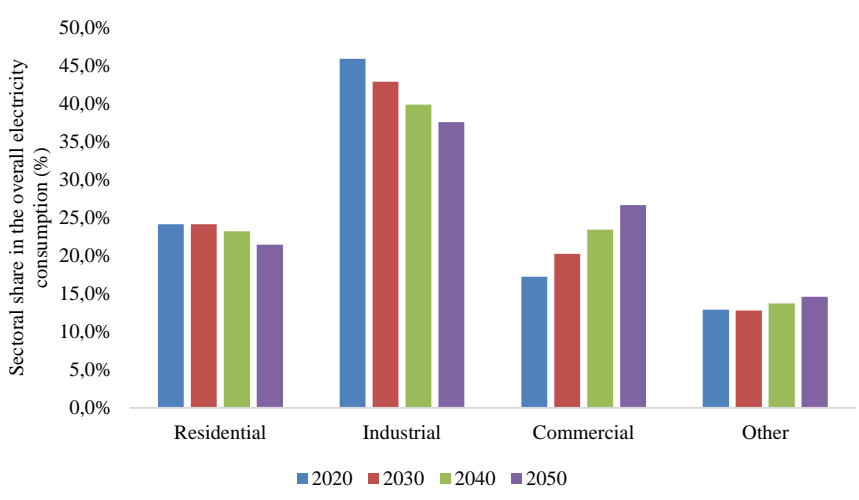

Fig. 16. Projected sectoral share in the overall electricity consumption in Brazil (\%). Source: Extracted from [9].

A sensitivity analysis was also undertaken considering specific input variables in order to verify the robustness of the obtained results. For the residential sector, the first sensitivity analysis is focused on considering a constant market penetration rate (between 2017-2050). In this case, our findings revealed the small impact of this variable in the overall hourly DR potential (GW) since only small changes were verified for daily hours. The impact of a constant market penetration rate, however, increases for night hours. In this case, due to the use of air-conditioning equipment during night the overall DR potential for this period of time is affected by an average value of $9 \%$. If no energy efficiency improvements would be considered between 2017-2050 for the residential sector (i.e.

\footnotetext{
${ }^{17}$ The only exception is for the South (particularly for 2050) in which the contribution of the commercial sector is slightly lower (i.e. $8 \%$ ) than the residential sector.
} 
fixing the specific energy consumption), the overall hourly DR potential (GW) is affected in average by $35 \%$ along a typical day. The impact of energy efficiency improvements for the industrial sector on the available DR potential are smaller and less noticeable than for the residential sector, since the considered gains in energy efficiency between 2017 and 2050 are smaller (see Table 7Table 7) than the ones considered for the residential sector.

\section{Conclusion}

This paper attempted to address a model-based assessment of the theoretical DR potential in the Brazilian power sector and our findings suggest several contributions to the current literature. Although extensive research has been carried out on different DR issues, to date, the research has tended to focus mostly on qualitative rather than quantitative assessments on DR potentials. To give a well-known example, fewer research studies have attempted to evaluate the theoretical DR potential for developing countries such as the case of Brazil. The strengths of this study include two central issues addressed: (1) a sectoral analysis (i.e. residential, commercial and industrial) was considered together with a (2) regional analysis (broadly splitting up the Brazilian power system into four main subsystems).

This study set out to test the hypothesis that the potential of DR in the power system evaluated in this research is expected to considerably increase in the long-term. Data for this study were collected using different sources including the future government prospects for the sector. The research is limited by the use of secondary data for future projections (e.g. market penetration rate, projected number of households and specific energy consumption). Data was linearly extrapolated when no specific data was available between periods. The methodology is based on a set of equations (1-9) which allows the calculation of the theoretical DR potential for each region, sector and process.

Our analysis reveals that the overall maximum hourly theoretical DR potential in Brazil is expected to double, increasing from $12.8 \mathrm{GW}$ in 2017 to almost $25.6 \mathrm{GW}$ by 2050 . The results point out that the majority demand-side response potential may lie in the industrial sector. Even considering the efficiency improvements, the load shedding and shifting potential for energy-intensive industries are projected to increase in the future years mainly due to the projected sectoral growth during the same 
period. Lower but a still substantial DR potential for the residential and commercial sectors were also identified. The high expected increase in the overall electricity DR potential for the residential sector is driven mainly by the increase in both the number of households and the number of appliances per house. For the residential sector, it can be noted that more than half of the DR potential is derived from refrigerators. The use of air-conditioning systems also represents a great contribution to the residential sector, with a particular high contribution between 22 p.m. and 6 a.m. The DR potential from air conditioning systems increases considerably between 2017 and 2050 and this is mostly because the number of buildings with this type of appliance is expected to substantially increase in the period.

Although the higher load flexibility potential is theoretically found to be in the industry sector, we did not address deeply the industrial processes characteristics in our assessments. It is worth mentioning that the high level of integration and dependence between industrial processes would affect the effectively achievable DR potential for the sector. The data availability for the commercial sector is much more restricted than for the industrial sector. For this reason, the annual electricity consumption available for DR was broadly estimated using the combination of each commercial individual process demand with its respective average demand share. The DR resources availability best matches the daily load curve of the power system for the commercial sector. These results provide further support for the hypothesis that this sector will develop a key role in offering more valuable load flexibility potential (i.e. when the power system mostly needs).

Unfortunately, part of our results is rather difficult to interpret because, to date, we have no sectoral load profile patterns available for the country. However, our findings provide support and evidence that the particularities of each region are strongly important to consider in future analysis. Further studies, which take these regional particularities into account, will need to be considered before the association between the sectoral and regional impacts of DR strategies. However, we highlight that future research studies would benefit from our findings since the results presented in this paper could be easily adapted to optimization (or simulation) long-term energy models. By making use of our 
results, future works could focus on several directions, addressing for example, to what extent can DR resources reduce supply costs and $\mathrm{CO}_{2}$ emissions or even assess to what extent DR can compete in terms of cost-effectiveness with other supply-side options.

Although this study has successfully demonstrated the high theoretical DR potential for Brazil, a number of limitations need to be noted regarding the present study. This study is unable to encompass the full assessment of the load flexibility potential in the country. Therefore, the scope of this research was limited in terms of the selected DR applications and other suitable processes/appliances should receive more attention in future analyses. Our findings are also somewhat limited because of the use of approximate data. Specifically, it is possible that our results were influenced by the lack of specific regional information. We highlight that a set of assumptions were made (e.g. estimated load profiles for each sector) in order to assess the DR potential for each region within the country. We also considered $100 \%$ of the flexible load potential. This is considered an optimistic assumption and of course, the achievable DR potential would be much lower. Therefore, the lack of data adds further caution regarding the generalisability of our findings. Also, we highlight that the DR potential largely depends on user acceptance and this category of DR potential is not taken into account in this study. This would imply in a lower load flexibility potential in reality. This limitation means that our findings need to be interpreted cautiously since only the theoretical DR potential was assessed, and no technical, economic or practical restrictions are considered. The DR contribution of electrical vehicles (EVs) is not assessed in this research mostly because of the lack of reasonable data for the sector. Although the EVs represent currently a low contribution in the country, for the future it is expected that this type of load would offer a significant demand-side flexibility potential. Thus, future works would address this potential flexible demand for the Brazilian power sector. In the case of Brazil, the DR potential largely depends on regulatory improvements to enable customer participation in DR initiatives. The growth of the IoT (Internet of Things) technology will also be disruptive and it is likely to develop a key role in the Brazilian power sector since the first regulation has been recently proposed in the country through the Law 9,854/2019. Our theoretical DR potential assessment, 
however, does not take into account the effects of IoT and further research is required to establish the potential influence of this technology in the overall theoretical DR potential. Further regulatory improvements frameworks and business models are fundamental to enable the demand-side potential in the country.

Therefore, this study tried to capture the most significant variables which would affect the longterm results. We also attempt to consider the model disaggregation, including the Brazilian regional characteristics. To summarize, despite the previously mentioned limitations, we highlight that the main aim of this work was to perform a first attempt to assess the current and the future theoretical DR potential across sectors and regions within the Brazilian power system and consequently bringing some light on this important issue for the country.

\section{ACKNOWLEDGEMENT}

This work is supported by the National Council for Scientific and Technological Development (CNPq), Brazil. This work has been supported by national funds through FCT - Fundação para a

Ciência e Tecnologia within the Project Scope: UID/CEC/00319/2019.

\section{References}

[1] IEA. Market Report Series: Energy Efficiency 2018. 2018.

[2] IRENA. Global Energy Transformation - A roadmap to 2050. 2018.

[3] Dranka GG, Ferreira P. Towards a smart grid power system in Brazil: Challenges and opportunities. Energy Policy 2020;136. doi:10.1016/j.enpol.2019.111033.

[4] Lund H, Østergaard PA, Connolly D, Mathiesen BV. Smart energy and smart energy systems. Energy 2017;137:556-65. doi:10.1016/J.ENERGY.2017.05.123.

[5] Lund H, Duic N, Østergaard PA, Mathiesen BV. Future district heating systems and technologies: On the role of smart energy systems and 4th generation district heating. Energy 2018;165:614-9. doi:10.1016/J.ENERGY.2018.09.115.

[6] Guelpa E, Marincioni L, Deputato S, Capone M, Amelio S, Pochettino E, et al. Demand side management in district heating networks: A real application. Energy 2019;182:433-42. doi:10.1016/J.ENERGY.2019.05.131.

[7] Pelda J, Holler S. Spatial distribution of the theoretical potential of waste heat from sewage: A statistical approach. Energy 2019;180:751-62. doi:10.1016/J.ENERGY.2019.05.133.

[8] Leitner B, Widl E, Gawlik W, Hofmann R. A method for technical assessment of power-toheat use cases to couple local district heating and electrical distribution grids. Energy 2019;182:729-38. doi:10.1016/J.ENERGY.2019.06.016.

[9] EPE. Nota Técnica DEA 13/15 - Demanda de Energia 2050 2016:232. http://www.epe.gov.br/sites-pt/publicacoes-dados-

abertos/publicacoes/PublicacoesArquivos/publicacao-227/topico-458/DEA 13-15 Demanda 
de Energia 2050.pdf (accessed February 19, 2016).

[10] ANEEL. Resolução Normativa No 547, de 16 de Abril de 2013 2013:5. http://www.aneel.gov.br/documents/656877/14486448/ren2013547.pdf/c891e96e-9d3043a0-870c-c1c4b725dbbd?version=1.0.

[11] ANEEL. Normative Resolution No 733. ANEEL 2016:3. http://www2.aneel.gov.br/cedoc/ren2016733.pdf (accessed February 28, 2018).

[12] ANEEL. Normative Resolution $\mathrm{n}^{\mathrm{o}} 610 . \quad 01 / 04 / 2014$ http://www2.aneel.gov.br/cedoc/ren2014610.pdf (accessed February 28, 2018).

[13] Di Santo KG, Kanashiro E, Di Santo SG, Saidel MA. A review on smart grids and experiences in Brazil. Renew Sustain Energy Rev 2015;52:1072-82. doi:10.1016/j.rser.2015.07.182.

[14] ANEEL. Normative Resolution $\mathrm{n}^{\mathrm{o}} \quad 792$ 2017:4. http://www2.aneel.gov.br/aplicacoes/audiencia/arquivo/2017/043/resultado/ren2017792.pdf (accessed February 28, 2018).

[15] Saebi J, Taheri H, Mohammadi J, Nayer SS. Demand bidding/buyback modeling and its impact on market clearing price. 2010 IEEE Int Energy Conf Exhib EnergyCon 2010 2010:791-6. doi:10.1109/ENERGYCON.2010.5771788.

[16] ONS. Brazilian National Grid Operator. 2019 2019. http://www.ons.org.br/Paginas/resultadosda-operacao/historico-da-operacao (accessed May 7, 2018).

[17] EPE. Plano Decenal de Expansão de Energia 2026. Ministério Minas e Energ 2017:264. http://www.epe.gov.br/pt/publicacoes-dados-abertos/publicacoes/plano-decenal-deexpansao-de-energia-pde (accessed February 10, 2018).

[18] Haider HT, See OH, Elmenreich W. A review of residential demand response of smart grid. Renew Sustain Energy Rev 2016;59:166-78. doi:10.1016/J.RSER.2016.01.016.

[19] O'Connell N, Pinson P, Madsen H, O'Malley M. Benefits and challenges of electrical demand response: A critical review. Renew Sustain Energy Rev 2014;39:686-99. doi:10.1016/J.RSER.2014.07.098.

[20] Shariatzadeh F, Mandal P, Srivastava AK. Demand response for sustainable energy systems: A review, application and implementation strategy. Renew Sustain Energy Rev 2015;45:34350. doi:10.1016/J.RSER.2015.01.062.

[21] Boßmann T, Eser EJ. Model-based assessment of demand-response measures-A comprehensive literature review. Renew Sustain Energy Rev 2016;57:1637-56. doi:10.1016/J.RSER.2015.12.031.

[22] Paterakis NG, Erdinç O, Catalão JPS. An overview of Demand Response: Key-elements and international experience. Renew Sustain Energy Rev 2017;69:871-91. doi:10.1016/j.rser.2016.11.167.

[23] Gils HC. Economic potential for future demand response in Germany - Modeling approach and case study. Appl Energy 2016;162:401-15. doi:10.1016/J.APENERGY.2015.10.083.

[24] Söder L, Lund PD, Koduvere H, Bolkesjø TF, Rossebø GH, Rosenlund-Soysal E, et al. A review of demand side flexibility potential in Northern Europe. Renew Sustain Energy Rev 2018;91:654-64. doi:https://doi.org/10.1016/j.rser.2018.03.104.

[25] Olkkonen V, Ekström J, Hast A, Syri S. Utilising demand response in the future Finnish energy system with increased shares of baseload nuclear power and variable renewable energy. Energy 2018;164:204-17. doi:10.1016/J.ENERGY.2018.08.210.

[26] Müller T, Möst D. Demand Response Potential: Available when Needed? Energy Policy 2018;115:181-98. doi:10.1016/J.ENPOL.2017.12.025.

[27] Gnann T, Klingler A-L, Kühnbach M. The load shift potential of plug-in electric vehicles with different amounts of charging infrastructure. J Power Sources 2018;390:20-9. doi:10.1016/J.JPOWSOUR.2018.04.029.

[28] AEG. State of Michigan Demand Response Potential Study - Technical Assessment. 2017.

[29] Dranka GG, Ferreira P. Review and assessment of the different categories of demand response potentials. Energy 2019;179:280-94. doi:10.1016/J.ENERGY.2019.05.009.

[30] Gils HC. Assessment of the theoretical demand response potential in Europe. Energy 
2014;67:1-18. doi:10.1016/J.ENERGY.2014.02.019.

[31] Gils HC, Simon S, Soria R. 100\% Renewable energy supply for Brazil-The role of sector coupling and regional development. Energies 2017;10. doi:10.3390/en10111859.

[32] Dranka GG, Ferreira P. Planning for a renewable future in the Brazilian power system. Energy 2018;164:496-511. doi:10.1016/j.energy.2018.08.164.

[33] Saunders M, Lewis P, Thornhill A. Research Methods for Business Students. Seventh ed. England: 2016. doi:10.1007/s13398-014-0173-7.2.

[34] Partners S. Demand Response: A study of its potential in Europe 2015:6. http://siapartners.com/insights/demand-response-study-its-potential-europe (accessed November 7, 2018).

[35] Pechmann A, Shrouf F, Chonin M, Steenhusen N. Load-shifting potential at SMEs manufacturing sites: A methodology and case study. Renew Sustain Energy Rev 2017;78:4318. doi:10.1016/J.RSER.2017.04.081.

[36] Gils HC. Balancing of Intermittent Renewable Power Generation by Demand Response and Thermal Energy Storage. University of Stuttgart, 2015.

[37] EPE. Plano Decenal de Expansão de Energia 2027. Ministério Minas e Energ 2017:341.

[38] ABAL. Bauxita no Brasil: Mineração Responsável e Competividade. São Paulo: 2017.

[39] EPE. Nota Técnica DEA - Cenário Econômico 2050. Brasília: 2015.

[40] USGS. 2014 Minerals Yearbook Brazil. 2017.

[41] Köppen's climate classification map for Brazil 2019. https://upload.wikimedia.org/wikipedia/commons/f/f9/Köppen_climate_types_of_Brazil.svg (accessed December 20, 2019).

[42] Alvares CA, Stape JL, Sentelhas PC, Leonardo J, Gonçalves M, Sparovek G. Köppen's climate classification map for Brazil n.d. doi:10.1127/0941-2948/2013/0507.

[43] EPE. Anuário Estatístico de Energia Elétrica. 2017. doi:10.1017/CBO9781107415324.004.

[44] Ministério de Minas e Energia. Portaria Interministerial Noº de 31 de Julho de 2018. Brazil: MME; 2018.

[45] PROCEL. Sistema de Informações de Posses de Eletrodomésticos e Hábitos de Consumo 2004. http://www.procelinfo.com.br/Sinpha (accessed November 20, 2018).

[46] Aduda KO, Labeodan T, Zeiler W, Boxem G, Zhao Y. Demand side flexibility: Potentials and building performance implications. Sustain Cities Soc 2016;22:146-63. doi:10.1016/J.SCS.2016.02.011.

[47] Energia M de M e. Portaria Interministerial No2, de 31 de Julho de 2018. MME; 2018. 


\section{Appendix A}

Table A.1: Input Data - Hourly Load Profile for Each Sector [36,45]

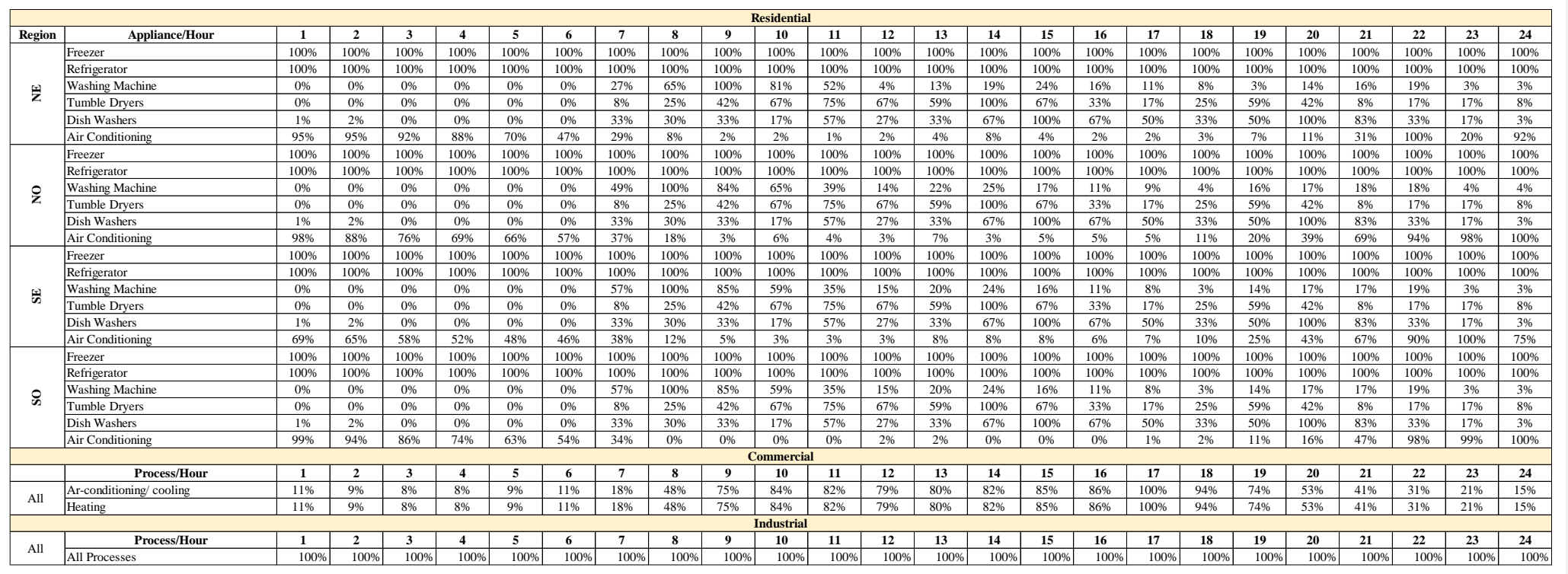

